\title{
Modeling The Performance Evaluation Of Local Investment And Economic Development Corporations
}

Frédéric Bernard $^{1}$, Solidarity Fund QFL, Canada

Jean Desrochers², (E-mail: Jean.Desrochers@usherbrooke.ca), Université de Sherbrooke

Denis Martel ${ }^{3}$, Université de Sherbrooke, Canada

Jacques Préfontaine ${ }^{4}$, (E-mail: jacques.prefontaine@usherbrooke.ca), Université de Sherbrooke, Canada

\begin{abstract}
The purpose of this research is to propose an overall performance evaluation model for local development companies that takes into account social, financial and operational aspects. ${ }^{5}$ While there are many ways to evaluate business performance, few make it possible to take into account all the objectives of the organization. After reviewing the literature on the topic, we developed a model that uses a surface measurement to classify organizations. We then applied this model to the Société locale d'investissement et de développement d'emploi du Québec (SOLIDEQ), which itself comprises 84 SOLIDEs. The mission of these organizations is to provide venture capital to regional companies. As an arm of a labor-sponsored venture capital corporation, the SOLIDEs must obtain a return on investment commensurate with the risk incurred, achieve local development objectives such as job creation and maintenance, and lastly, manage operations wisely given that the management committee consists of volunteers. The study results show that our model can be effectively used to measure the performance of each SOLIDE and to create a classification that takes into account all their objectives.
\end{abstract}

\section{INTRODUCTION}

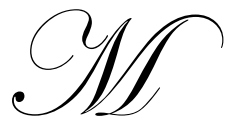

easuring the performance of non-profit organizations or companies with more than financial objectives is a delicate matter. In these types of organizations, the objectives often appear to be contradictory. For example, it may seem incompatible for a company to offer the best working conditions and at the same time seek to maximize profits. Some managers will successfully meet these challenges while others will only partially achieve them. It therefore becomes imperative to evaluate the performance of managers based on all the objectives rather than on individual ones.

This research seeks to develop a performance evaluation model that will allow classification of non-profit organizations or social for-profit organizations. Beginning with a review of the literature on traditional performance measures, we then propose an evaluation model that will provide an empirical evaluation measurement. This is followed by a presentation and analysis of the study results, and lastly, by the conclusions and an overview of potential future research.

\footnotetext{
${ }^{1}$ Financial analyst at the Solidarity Fund QFL (Regional fund)

${ }^{2}$ Professor and director of the Équipe de Recherche en Capital de Risque, Université de Sherbrooke

${ }^{3}$ Professor and assistant-dean of Research, Faculty of Administration, Université de Sherbrooke

${ }^{4}$ Professor and director of the Chaire Desjardins en Développement Durable

${ }^{5}$ Other aspects may be used depending on the context.
} 


\section{REVIEW OF LITERATURE}

Forbes (1998) documented the empirical studies conducted on the effectiveness of non-profit organizations from 1977 to 1997 (covering primarily U.S. studies). Although these studies rarely pertained to local development organizations, the measurement problem is nonetheless relevant to the organizations discussed in this paper. Forbes discovered that while there are various ways of viewing effectiveness, certain constants emerge. He identified four main ways of measuring effectiveness:

- $\quad$ The goal attainment approach assumes that all the goals of the organization are clearly and unequivocally identifiable.

- The system resource approach is defined as the ability of the organization to exploit the resources of its environment, which may be political, economic or even institutional.

- The reputational approach characterizes effectiveness according to the opinion of the key people in its environment (clients, professionals, partners, etc.).

- The social constructionist or emergent approach is the most recent and focuses on developing processes to measure effectiveness and will be examined in greater detail later on.

The author gives three main reasons why evaluating the performance of non-profit organizations is difficult: first, because their legal and financial status precludes using traditional performance tools; second, because the very definition of effectiveness is ambiguous, and third, because in most cases the services offered are intangible.

A second review of the literature, conducted by researcher Maxime Simoneau (2002) for Groupe de recherche sur le capital de risque of the Université de Sherbrooke (GRCR), provided a closer look at the most sophisticated performance measurement methods. The methods listed by this work stemmed primarily from the emergent approach as defined earlier by Forbes.

Over the past decade, Norton and Kaplan (2001) developed a new performance measurement technique referred to as the "balanced scorecard." This method assumes that the degree to which an organization achieves its mission is the most important component of performance measurement. Concretely, it is an integrated group of performance metrics set up to better orient the organization's strategy. The aspects covered are: financial performance, customer relations, internal business processes, and organizational learning and development. These aspects must contain metrics that go hand-in-hand with the corporate mission, strategy, technology and culture. This method naturally presupposes that clear objectives have been formulated since otherwise, no metric would be possible.

Researchers O. Renz and Herman (1998) also left their mark in the sphere of NPO effectiveness evaluation. Considered avant-garde, their research sought to create a model that could distinguish between effective and less effective NPOs. To this end, they administered a questionnaire to individuals who have or have had a special relationship with NPOs. The sample consisted predominantly of management staff, executive presidents and founding members of well-known NPOs who were asked to describe the effectiveness of their organization based on nine aspects: financial management, human resource management, public relations, government relations, fundraising, distribution programs, volunteer work, relationship with the community, and lastly, the management committee.

The first observation was that it is impossible to construct a general effectiveness index adapted to all types of NPOs. It is essential to take into account the particular characteristics inherent to each organization because the differences between them are too great. The second was that adopting various management practices such as needs evaluation, strategic planning and cost reduction programs would promote greater organizational effectiveness.

In a recent study conducted for the industrial relations department of Université Laval, Quarter and Carmichael (2001) confirmed the lack of an index to measure the social impact of an investment fund. This same study shows that very little research has been conducted on the return social investment funds have to sacrifice. Of the few studies that do exist, one carried out by Dowell and Hart (2000) concluded that no returns are sacrificed. This study compared the annual results of ethical funds versus traditional mutual funds with similar risk (volatility). 
For our purposes, the most important aspect of Quarter's and Carmichael's research is the creation of an index measuring the extent of social investment by the funds analyzed. In order to weigh the funds' social involvement, the authors isolated eight elements, which were formulated as questions and posed to fund managers (the sample consisted of 189 funds):

- $\quad$ Does your fund have a formal process for judging the ethical criteria of its investments?

- Has your fund had to withdraw from or boycott an investment for social reasons?

- Does your fund invest in certain companies because in addition to promising attractive returns, they have a social aspect that you would like to support?

- Does your fund invest in others funds that focus on social criteria, for example, an ethical fund focused on the environment?

- Does your fund submit proposals to the shareholders of the portfolio companies?

- Have you invested in projects aimed at community economic development?

- Have you invested in projects aimed at regional economic development?

- Has your fund invested in social housing programs?

The results were very telling, as $69 \%$ of people answered "no" to all the questions, $19 \%$ answered "yes" to only one of the questions, $6 \%$ responded "yes" to two questions, $5 \%$ to three, $2 \%$ to four, and $0.005 \%$ to five (the maximum number of possible "yes" answers).

The second step involved seeing which characteristics were likely to influence the funds' propensity to favor social aspects in their investments. The study targeted the following determining characteristic as leading to high scores on the social involvement index: the fund's region of origin, its size (capitalization and number of investors), the presence of union members on the executive board, the executive board's attitude towards social causes, the training formula used for directors, and the commitment to fiduciary responsibilities. In his study, Carmichael (2000), for his part, isolated the determining characteristics for social engagement of pension funds in British Columbia: leadership, support, expertise and directors' level of education.

Therefore, the main conclusion drawn by the Quarter study was that many factors influence how much emphasis an investment fund places on social investment. This conclusion is confirmed by the fact that the vast majority of funds sensitive to social impact are based in Quebec: "Quebec seems to have the greatest number of factors; the context in Quebec appears to be more conducive to social investment.

\section{CREATING A PERFORMANCE INDEX}

As mentioned in the theoretical framework, the overriding purpose of this research is to create an index that can reflect, among other things, the social development and financial aspects. A third facet, the one associated with the internal operation of the SOLIDE, will be included in the index to reflect the quality of the SOLIDE's operation. By combining these three aspects, a composite index will be obtained illustrating the SOLIDE's overall effectiveness. Diagram 1 illustrates the composition of the overall effectiveness of a SOLIDE according to the model developed.

In keeping with our earlier observation, the effectiveness index is based on the following characteristics:

- $\quad$ A construct of the participants involved

- $\quad$ Specific to the context in which the company operates

- $\quad$ Able to evolve in step with the players involved.

Moreover, its measurement will comprise an integrated group of performance metrics in accordance with the balanced scorecard concept. The three components selected for the index are financial performance, social impact and internal general processes. 
Diagram 1: Explanation of overall effectiveness

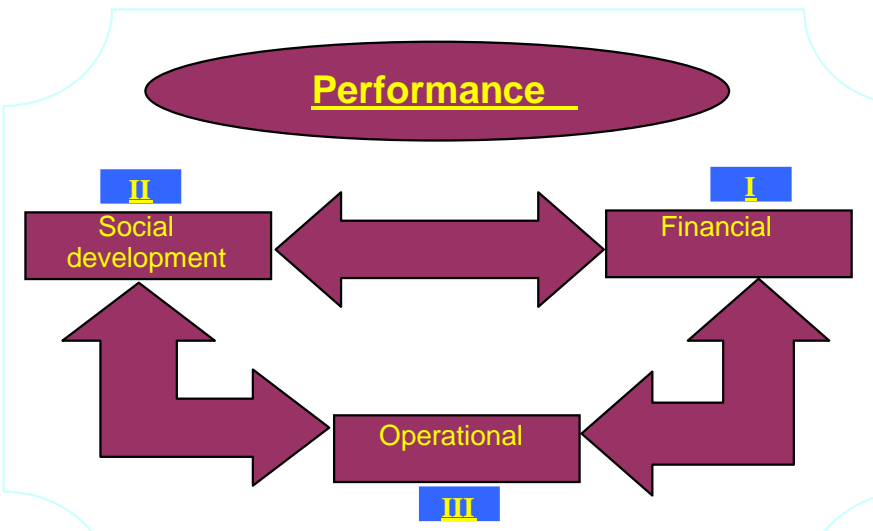

\section{Definition Of The Three Components}

Financial component: This is by far the most determining aspect of the SOLIDE's overall effectiveness. Indeed, failing to maintain minimum profitability standards could compromise the Fund's very survival. While the returns of the SOLIDEs are not expected to compare to those in the VC world, they must at least be sufficient to ensure the organization's survival. Given its importance, the financial aspect is double-weighted in the index.

The following four key ratios comprise the evaluation criteria for the financial component:

- $\quad$ Average two-year return

- $\quad$ Average one-year return on available funds (SOLIDE capital plus retained earnings)

- Aggregate capital return (last year's revenue plus retained earnings divided by the capital since the SOLIDE's creation).

- $\quad$ Total losses on disbursements.

The first three ratios are profit ratios used to determine whether the SOLIDE generates attractive short- and long-term returns on its investments and cash assets. The fourth indicates investment quality. For example, if the board of directors accepts marginal projects, there will be substantial losses on the amounts disbursed, hence a high ratio. In contrast, a very low ratio reflects promising investments.

The social development component: This component is intended to illustrate whether the SOLIDE achieves the social aspects of its mission. While difficult to quantify, it is essential to have an indicator for this component. Given that the very mission of a SOLIDE revolves around social development, the degree to which its mission is achieved becomes an important component of the index. The mission of a SOLIDE as described in its incorporating act, is as follows:

The SOLIDE manages an investment fund with a view to providing financial and technical help to existing and new businesses in order to create and maintain jobs in the CMA and eligible municipalities.

The stated objectives of the SOLIDE are as follows:

- $\quad$ "Further the creation of small viable companies and contribute to their development."

- "Support job creation and local economic activity." 
- $\quad$ "Acquire expertise in business creation and development capital management in the CMA and eligible municipalities."

- "Facilitate job creation by developing a local intervention strategy."

The SOLIDE's senior management use these objectives as a guide when determining the variables that will be used to evaluate their social development performance:

- The average cost of a job created

- $\quad$ The average number of jobs per project

- $\quad$ The development lever (number of indirect jobs created)

- $\quad$ The extent of the SOLIDE's activities (evaluated by the SOLIDEQ advisor)

- Integration of the SOLIDE within the management organization (evaluated by the SOLIDEQ advisor)

- Interest shown by the board of directors in the SOLIDE (evaluated by the SOLIDEQ advisor)

- $\quad$ Concern for the social impact of investments (evaluated by the SOLIDEQ advisor).

It should be noted that the metrics are initially aimed at determining job creation. The first three metrics measure the effectiveness of job creation. The four others seek to determine the SOLIDE's involvement in its environment, i.e., whether it works as a team with development agents or whether it works alone. The extent to which the objectives are achieved is directly correlated with the SOLIDE's integration level and number of jobs created.

The operational component: No effectiveness index can be considered complete without a component pertaining to the internal operational process. This component is also made necessary by the obligation imposed by SOLIDEQ on the SOLIDE to effectively structure their investment process. As a majority shareholder in the SOLIDE funds and having an educational and training mission, SOLIDEQ sets high management standards. This specific context, which is included in the index, is consistent with the characteristics required by the emergent trend.

To recap, the following variables are used to estimate the operational component:

- $\quad$ Competence of the SOLIDE analysts (evaluated by the SOLIDEQ advisor)

- Investment follow-up (evaluated by the SOLIDEQ advisor)

- $\quad$ Prospecting (evaluated by the SOLIDEQ advisor)

- $\quad$ Relationship with SOLIDEQ (evaluated by the SOLIDEQ advisor)

Technical Characteristics Of The Index

With a view to making the performance index more representative of the three components selected, we used a model developed by Weiss (2004), an investment fund financial analyst stationed in Geneva. Specializing in ethical investment, this analyst has, over the years, developed a specific model to obtain an overall evaluation of the financial and social component of companies whose securities might be purchased by an ethical mutual fund.

\section{THE RESULTS}

This model has the advantage of offering a visual presentation of the strengths and weaknesses according to each component. With this index, the SOLIDEs are evaluated with the same overall scoring but from different sources, thus providing more details than a simple effectiveness score. Diagram 2 illustrates this concept more clearly: 


\section{Diagram 2 Concept of surface effectiveness}

EFFECTIVENESS SURFACE

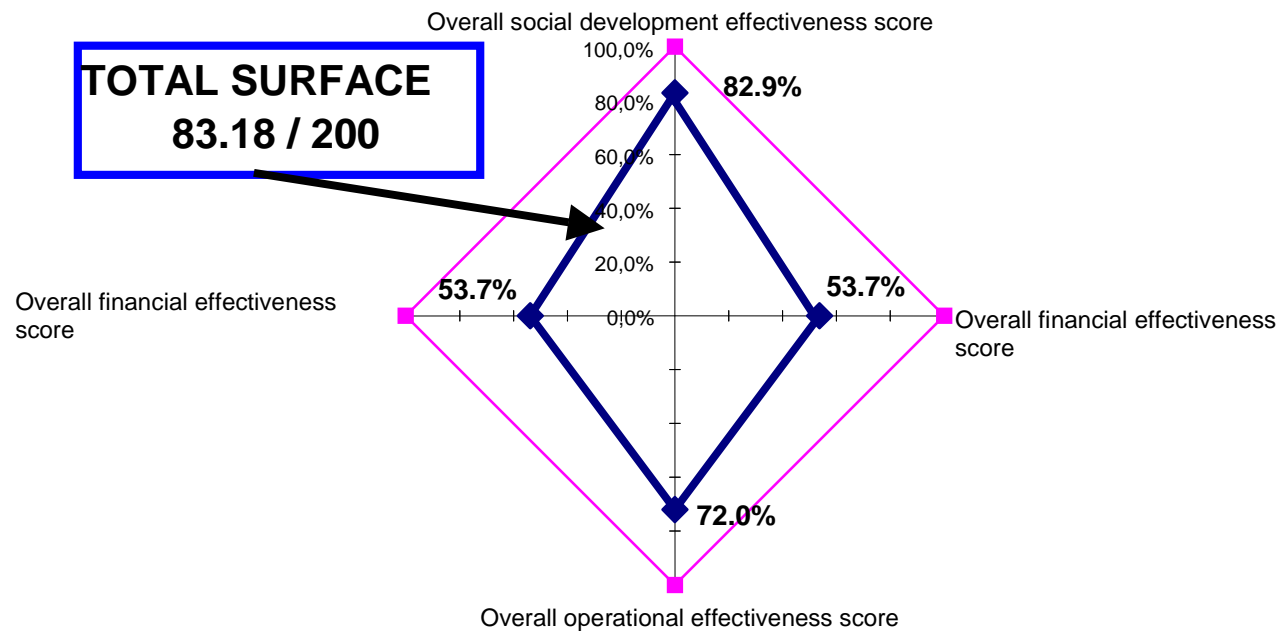

The values are presented as a percentage of the maximum value of the component, i.e., 10. For example, for the surface calculation, ${ }^{6} 53.7 \%$ is equal to $5.37 / 10$. Therefore, the total possible surface is 200 and is represented by the line outside the diamond. For its part, the SOLIDE obtained a surface of 83.16. We quickly see that its financial performance is $53.7 \%$, which is very low compared with its social development performance of $82.9 \%$.

This way of making up the index has several advantages for the director. In fact, the surface measurement makes it possible to classify all the SOLIDEs based on the individual criteria and on all the criteria combined. By examining the diagram's surface, the analyst can see the organization's weakness in a given area, allowing him to quickly intervene. Tables 1 and 2 present the results of the 10 best and worst performing SOLIDEs based on the total surface measurement.

Table 1 Top 10 SOLIDEs

\begin{tabular}{|c|c|c|c|c|}
\hline $\begin{array}{c}\text { SOLIDE } \\
\text { Ranking }\end{array}$ & $\begin{array}{c}\text { Financial Effectiveness } \\
\text { Indicator }\end{array}$ & $\begin{array}{c}\text { Social Effectiveness } \\
\text { Indicator }\end{array}$ & $\begin{array}{c}\text { Operational } \\
\text { Effectiveness Indicator }\end{array}$ & $\begin{array}{c}\text { Overall Performance } \\
\text { Indicator }\end{array}$ \\
\hline 1 & $0.95(6.5)$ & $0.97(01)$ & $0.85(3.5)$ & 172.49 \\
\hline 2 & $0.98(4.5)$ & $0.84(11)$ & $0.88(1.0)$ & 167.42 \\
\hline 3 & $1.00(1.5)$ & $0.93(03)$ & $0.74(17)$ & 166.86 \\
\hline 4 & $0.95(6.5)$ & $0.78(20)$ & $0.87(2.0)$ & 156.75 \\
\hline 5 & $0.87(16.0)$ & $0.87(06)$ & $0.85(3,5)$ & 148.07 \\
\hline 6 & $0.81(24.0)$ & $0.94(02)$ & $0.83(6.0)$ & 143.41 \\
\hline 7 & $0.88(12.5)$ & $0.84(10)$ & $0.76(12)$ & 140.00 \\
\hline 8 & $0.88(12.5)$ & $0.90(04)$ & $0.70(23)$ & 140.00 \\
\hline 9 & $0.93(8.0)$ & $0.69(32)$ & $0.75(14)$ & 132.80 \\
\hline 10 & $0.80(25.0)$ & $0.82(13)$ & $0.81(8.5)$ & 130.17 \\
\hline
\end{tabular}

\footnotetext{
${ }^{6}$ The total surface consists of two triangles. The upper triangle has a surface of $(20 \mathrm{x} 10 / 2=100)$ and the lower triangle has a surface of $(20 \times 10 / 2=100)$, or 200 for the figure. Thus, the upper triangle yields $(10.74 \times 8.29 / 2=44.52)$ while the lower triangle yields $(10.74 \times 7.2 / 2=38.66)$ for a total surface of $83.16 / 200$.
} 
The value of each individual performance is presented as a percentage in Tables 1 and 2 . The number in brackets indicates the SOLIDE's position in the individual ranking; the numbers containing a fraction indicate that there is equality between the SOLIDEs, which was broken down using the Spearman ranking methodology.

Table 2 Bottom 10 SOLIDEs

\begin{tabular}{|c|c|c|c|c|}
\hline SOLIDE Ranking & $\begin{array}{c}\text { Financial Effectiveness } \\
\text { Indicator }\end{array}$ & $\begin{array}{c}\text { Social Effectiveness } \\
\text { Indicator }\end{array}$ & $\begin{array}{c}\text { Operational } \\
\text { Effectiveness Indicator }\end{array}$ & $\begin{array}{c}\text { Overall Performance } \\
\text { Indicator }\end{array}$ \\
\hline 71 & $0.38(67)$ & $0.34(76)$ & $0.35(72.5)$ & 25.99 \\
\hline 72 & $0.31(73)$ & $0.53(59)$ & $0.30(76.0)$ & 25.64 \\
\hline 73 & $0.29(74)$ & $0.34(77)$ & $0.50(59.5)$ & 24.08 \\
\hline 74 & $0.32(71)$ & $0.29(79)$ & $0.38(71.0)$ & 21.17 \\
\hline 75 & $0.23(76)$ & $0.40(74)$ & $0.40(69.5)$ & 18.52 \\
\hline 76 & $0.15(78)$ & $0.55(57)$ & $0.58(49.0)$ & 16.14 \\
\hline 77 & $0.25(75)$ & $0.55(78)$ & $0.08(80.0)$ & 15.60 \\
\hline 78 & $0.17(77)$ & $0.50(66)$ & $0.28(78.0)$ & 12.98 \\
\hline 89 & $0.13(79)$ & $0.44(71)$ & $0.48(63.5)$ & 11.80 \\
\hline
\end{tabular}

An examination of Table 1 clearly shows that the SOLIDEs' overall ranking differs from the individual rankings. For example, SOLIDE 1 ranks first using the overall performance metric. It also ranks first in terms of social performance, in position 6.5 based on financial performance, and third for operational performance. Thus, the analyst and the advisor can intervene in the area of weakness with a view to helping the organization better achieve its objectives. We draw your attention to the SOLIDE that ranks 5th out of 80. This SOLIDE's financial performance is relatively weak. Consequently, the advisor could incorrectly assume that it has failed to achieve its objectives. However, although this SOLIDE does not rank at the top for two metrics, it is faring quite well at the organizational level. Therefore, the support team of SOLIDE analysts could intervene to help it at the financial level and thus improve its overall performance, which for all intents and purposes, is quite good. The advantage of using this method is that it allows the user to clearly see the situation and better target the interventions.

Diagram 3 Surface effectiveness and performance of SOLIDE 1

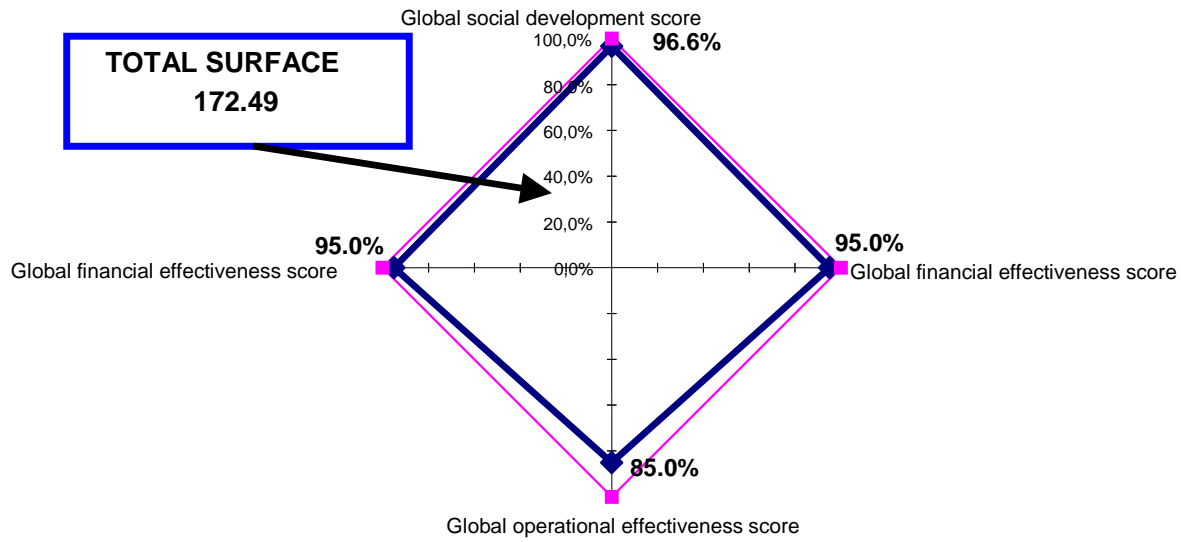


A look at Table 2 also shows the weaknesses of the SOLIDEs with the lowest overall performances. The last SOLIDE's operational performance is quite poor in finance and social development. However, it fares quite well in terms of organizational effectiveness. Diagrams 3 and 4 illustrate these observations for the first and $80^{\text {th }}$ SOLIDE, respectively.

As Diagram 3 shows, SOLIDE 1 covers almost the entire surface, meaning it requires little improvement. The analyst does not have a lot of work to do. In contrast, the SOLIDE in Diagram 4 shows a very weak performance. Visually, the analyst can quickly see the objectives that have not been achieved and prepare sounder advice.

Diagram 4 Effectiveness surface and performance of SOLIDE 80

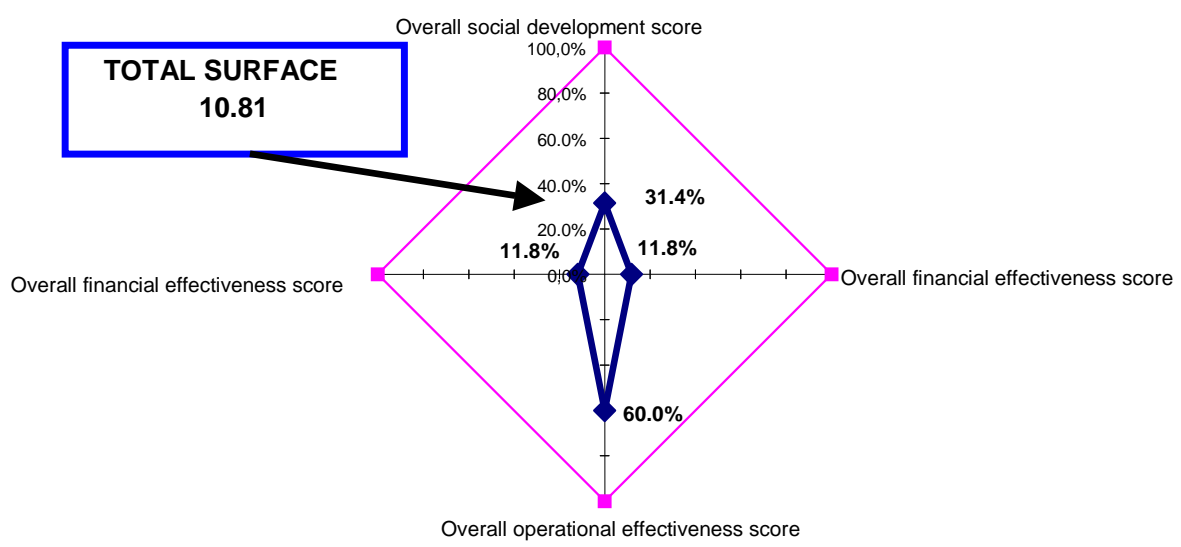

\section{CONCLUSION AND SUGGESTIONS FOR FUTURE RESEARCH}

In this article, we have shown a new way of evaluating the performance of a local development company with social and operational objectives that are complementary to its financial goals. The proposed model uses a surface concept that allows the user to classify firms according to overall performance. As well, analysts examining the ranking can visually determine in which of three areas, financial or operational or social, the organization's weakness or weaknesses lie. We plan to pursue similar investigations in order to generalize the process so that it can be used to evaluate the performance of heterogeneous organizations.

Our future research will take a closer look at the content of the components and variables that make up the effectiveness metric. Are the weightings adequate to accurately evaluate each component? We will also generalize the model in order to include companies from different industries or organizations. For example, what is the best ethical fund, and which company practices sound sustainable development management while achieving profitability targets?

\section{ACKNOWLEDGEMENTS}

This research was funded by the Groupe de Recherche en Capital de Risque of the Chaire Desjardins en Développement Durable at the Université de Sherbrooke 


\section{REFERENCES}

1. Bernard, Frédéric, (2003). Établissement d'une mesure de performance pour un fonds de développement local; Master's thesis; unpublished.

2. Carmichael, Isla. (2000). Union Pension Funds, Worker Control, and Social Investment in Canada. Toronto: University of Toronto, Unpublished doctoral dissertation.

3. Clarke, T. (2001). Balancing the Triple Bottom Line: Financial, Social and Environmental Performance. Journal of General Management, 26, 16-27.

4. Davenport, K. (2000). Corporate Citizenship: A Stakeholder Approach for Defining Corporate Social Performance and Identifying Measures for Assessing it. Business \& Society, 39, 210-219.

5. Dowell Glen, Stuart Hart (2000). Do Corporate Global Environmental Standards Create or Destroy Market Value, Management Science, Vol. 46, No.8, pp. 1059-1074.

6. Forbes, D. (1998). Measuring the Unmeasurable: Empirical Studies of Non-profit Organization Effectiveness from 1977 to 1997. Non-profit and Voluntary Sector Quarterly, 27, 183-202.

7. Holland, T. \& Jackson, D. (1998) Measuring the Effectiveness of Non-profit Boards. Non-profit and Voluntary Sector Quarterly, 27, 159-182.

8. Kaplan, R. (2001). Strategic Performance Measurement and Management in Non-profit Organizations. Nonprofit Management \& Leadership, 11, 353-370.

9. Kaplan, R., \& Norton, D. (2001). Transforming the Balanced Scorecard From Performance Measurement to Strategic Management: Part II. Accounting Horizons, 15, 147-160.

10. Kravchuk, R., \& Schack, R. (1996). Designing Effective Performance Measurement Systems under the Government Performance and Results Act of 1993. Public Administration Review, 56, 348-358.

11. Lévesque, B. (2000). Originalité et impact de l'action des SOLIDE sur le développement local et sur l'emploi au Québec. CRISES, Working Papers 0012, 20 pages.

12. Quarter J., Carmichael, I., (2001). Social Investment By Union-Based Pension Funds And Labor-Sponsored Investments. Relations Industrielles, Québec.

13. Renz D., Herman D.R. (1998). Non-profit Organizational Effectiveness: Contrasts Between Especially Effective and Less Effective Organizations. Non-profit Management and Leadership, San Francisco.

14. Simoneau, M. (2002). Intervention sur les mesures de performances. Essai-intervention pour l'obtention du grade de M.SC en finance. Université de Sherbrooke, unpublished.

15. SOLIDEQ Web site: www.solideq.qc.ca

16. Weiss, Pierre (2004). Les fonds de développement durable et éthique: sélection des titres; Speech delivered in Geneva in UN premises; unpublished.

17. Willis, A. (2001). Aligning Performance Measurements with Organizational Strategies. Hospital Material Management Quarterly, 54-63.

18. Youssofzai, F. (2000). La gestion stratégique des organisations-non-productrices-de-profit. Non-profit organizations: une revue de la littérature théorique sur les NPO. CRISES/UQAM, Working Papers Collection. No. 0005,70 pages.

19. Zéghal, D. 1993. Performance Measurement And Reporting in Non-Profit Organizations. CGA Accounting Research Centre, 39 pages. 


\section{NOTES}

